International Journal of Engineering \& Technology, $7(3.6)(2018)$ 64-67
International Journal of Engineering \& Technology
SPC
Website: www.sciencepubco.com/index.php/IJET
Research paper

\title{
Parametric Study of Stiffeners in Steel Composite Tub Girders
}

\author{
Silpa Pushpangadan ${ }^{1 *}$, Arjun S. Menon ${ }^{2}$, A. Sofi ${ }^{3}$ \\ ${ }^{1}$ Student, M. Tech Structural Engineering, Department Of Structural And Geotechnical Engineering, VIT, Vellore. \\ ${ }^{2}$ Structural Engineer, Sreegiri Consultants, Kochi. \\ ${ }^{3}$ Associate Professor, Department Of Structural And Geotechnical Engineering, VIT, Vellore.
}

\begin{abstract}
Closed structural sections (rectangular, circular, trapezoidal shape) possess high rotational rigidity compared to open sections like I girder. For highly curved bridges, closed sections with high torsional rigidity is an absolute choice. This paper suggests the use of steel composite Tub girder instead of concrete I girder in rail bridges. Stiffeners were used to strengthen the girder. Deflection and stress study has been done for the entire girder on various thickness of stiffeners under different loading.
\end{abstract}

Keywords: Closed section, stiffeners, Deflection, stress study.

\section{Introduction}

In India most of the metro- rail bridges are made of concrete, which is costlier, very low tensile strength compared to other binding materials, less ductile, contains soluble salts which causes efflorescence and has a huge self-weight. By pre stressing the concrete, tensile strength and ductility property can be improved significantly and dead load effects can be eliminated by using better material properties. But still it's a costlier process. An excellent alternative for this issue is usage of steelcomposite girder instead of concrete girder. In steel girders, closed sections those having circular, rectangular, trapezoidal shape has high rotational rigidity compared to open section such as I girders. Closed sections with high torsional rigidity is the better option for curved bridges. In this case large torsional forces is expected to act on the structure.

Bridge design is controlled by stiffness, not strength. Throughout construction, stresses were well below the yield stress. Longitudinal stiffeners are provided, location of longitudinal stiffeners on curved girders contribute to strength property. Adequate transverse stiffener is required for developing shear post buckling resistance.

Steel box girders are designed to act compositely with concrete deck on the finished bridge. Box section is closed by concrete deck and the bottom flange, two webs, and two top flanges comprise of steel girder. The sloping webs of the girders leads to trapezoidal shape giving its name as trapezoidal box girders. Slopping webs gives the sleek appearance, enhances the overall aesthetics and also reduces the bottom flange width. Smaller width reduces the amount of materials required and local plate buckling around supports where the bottom flange is in compression. Steel - composite tub girders are chosen because of structural efficiency and economy reasons. Different structural forms are chosen for various applications such as highway bridges, railway bridges and footbridges.

Longitudinal stiffeners are used to avoid local buckling in compression and shear zones. These stiffeners increase bending and shear strength of the girder. Transverse stiffener is used to improve the shear capacity of girder. Studies says that the effectiveness of stiffener is related to stiffener size and location.

\section{Governing Equation}

Permissible bending compressive/tension stresses at top \& bottom flanges of steel girder [9]

Permissible compressive stress at top flange is taken as smaller of the following two. First is computed as per clause no 508.6.2 of [9] (bending compression) considering whole bare steel girder with unsupported length of compression flange equals to effective span of the girder. Second is computed as per clause no 511.3.3 of [9] (axial compression) considering top flange plates only where unsupported length of compression flange is taken as the panel distance of top lateral truss.

Permissible bending compressive stress $\sigma \mathrm{bc}=0.66 \times \mathrm{f}_{\mathrm{cb}} \times \mathrm{fy} /$

$\left[(\mathrm{f} c b)^{1.4}+\left(\mathrm{f}_{\mathrm{y}}\right)^{1.4}\right]^{1 / 1.4}$ Where,

Elastic critical stress, $\mathrm{f}_{\mathrm{cb}}=\mathrm{k}_{1}\left[\mathrm{X}+\mathrm{k}_{2} \mathrm{Y}\right]\left[\mathrm{c}_{2} / \mathrm{c} 1\right]$ Permissible

maximum bending stress $\sigma \mathrm{b}=0.62 \mathrm{fy}$

\section{Numerical Investigation}

\section{Software - SAP2000}

SAP2000 is an ideal software developed for analysis and design of any type of structural system. Software is frequently used in the field of civil engineering. Any type of geometry ranging from the simple to complex, 2D to 3D can be modelled, analyse and designed. SAP2000 can make the best and most effective model or section using innate object - based modelling environment that smoothens the engineering process which is practical in addition. Advanced features such as nonlinear and dynamic analysis is also available.

Software contained with integrated templates for modelling, loading arrangements based on codes (almost all country codes are available, we can choose accordingly), advanced analysis are available, optimization of design, and customized reports make 
SAP2000 one of the best professional as well as commercial software available in the market.

\section{Model}

Basic model is prepared from the sectional and plan drawings of the girder. The model has created in SAP2000. Linear static analysis has been done with assigned moving load. Stiffeners are provided in the girder throughout the span. Stiffeners are provided at the bottom, side and across the side plate (vertically). Stiffener provided at the bottom plate along the longitudinal direction is known as bottom stiffener. Those provided at the side plate along the longitudinal direction is known as web stiffener. That provided at the side plate along transverse direction is known as vertical stiffener. Load cases provided as per the design including two moving loads. These moving loads are train load, here the train load is the load of rolling stock of Kochi metro rail. Longitudinal stiffeners are spanning throughout the length and transverse stiffeners are spanning throughout the depth of girder. Stiffeners are used to avoid local buckling in compression and shear zones. Results an increase in bending and shear strength of the girder and improves the shear capacity of the girder. Studies says that the effectiveness of stiffener is related to stiffener size and location. This paper studies the effectiveness of stiffeners provided to the girder. For this purpose the thickness of stiffener is varied for the selected loadings. Load cases selected for the study are: rolling stock on the both girders at the same time (DL+ LL + Veh $A+B)$ and rolling stock on one girder at a time (DL+ LL+ Veh $\mathrm{A} / \mathrm{B})$. Thickness range selected for study are $12 \mathrm{~mm}, 14 \mathrm{~mm}, 16 \mathrm{~mm}$, $18 \mathrm{~mm}, 20 \mathrm{~mm}, 25 \mathrm{~mm}$

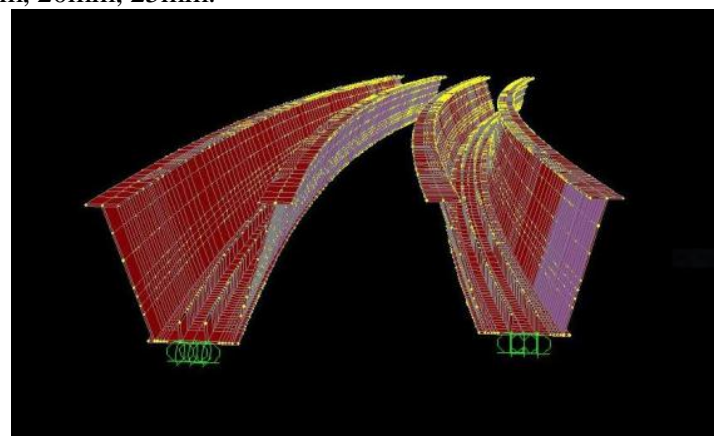

Fig. 1: Steel girder with stiffeners modelled in SAP2000

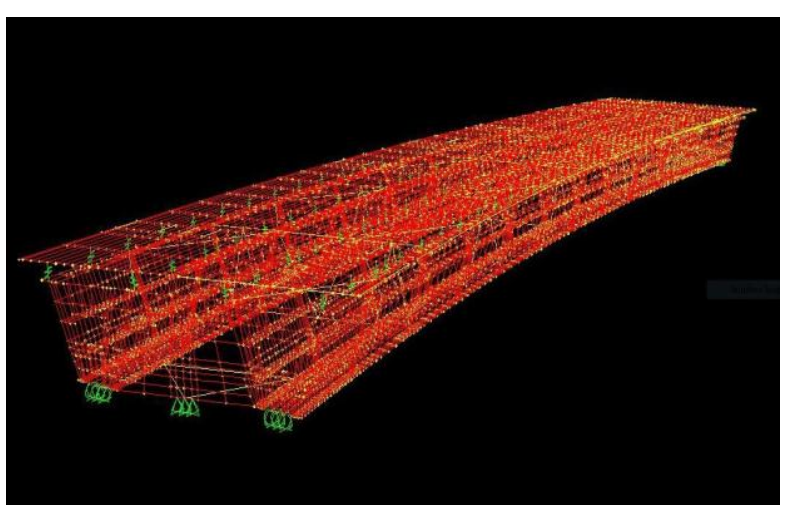

Fig. 2: Steel - composite tub girder modelled in SAP2000

\section{Material Property}

Table I: Material Properties of Steel Composite Tub Girder

\begin{tabular}{|l|l|}
\hline Grade of steel, fy & $350 \mathrm{MPa}$ \\
\hline Grade of concrete, fck & $40 \mathrm{MPa}$ \\
\hline Shear modulus Gs & $80.77 \mathrm{MPa}$ \\
\hline Shear modulus Gc & $13.54 \mathrm{MPa}$ \\
\hline Modulus of elasticity Es & $210.00 \mathrm{GPa}$ \\
\hline Modulus of elasticity Ec & $32.50 \mathrm{GPa}$ \\
\hline Unit weight of steel & $78.50 \mathrm{kN} / \mathrm{m}^{3}$ \\
\hline Unit weight of concrete & $25.00 \mathrm{kN} / \mathrm{m}^{3}$ \\
\hline Avg. depth of metal deck & $26.00 \mathrm{~mm}$ \\
\hline
\end{tabular}

\section{Analysis and Discussion}

\section{Static analysis}

A linear static analysis was carried out for $40 \mathrm{~m}$ curved steel tub girder. Since stiffeners are running throughout the span, study is conducted for varying thickness of the stiffeners and stress induced on the girder. The study is conducted for bottom stiffener, web stiffener and vertical stiffener under selected loading conditions.

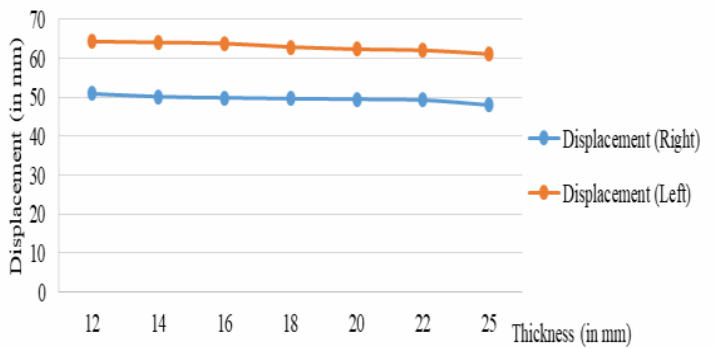

Fig. 3: Displacement V/s thickness of bottom stiffener, when vehicle loading is given to both girders

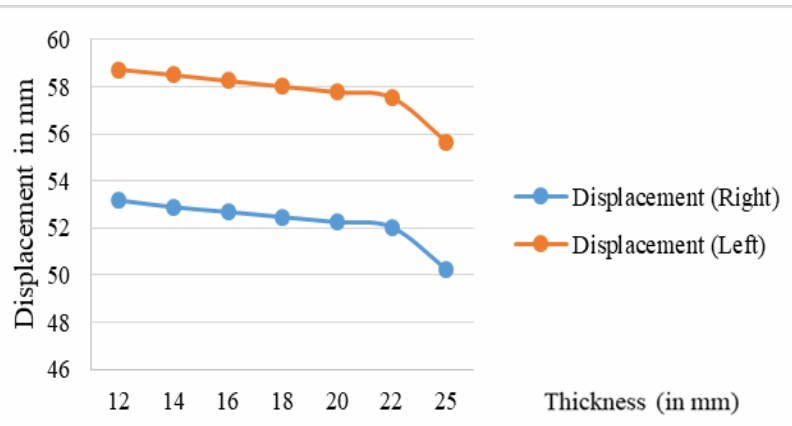

Fig. 4: Displacement V/s thickness of bottom stiffener, when vehicle loading is given to only one girder

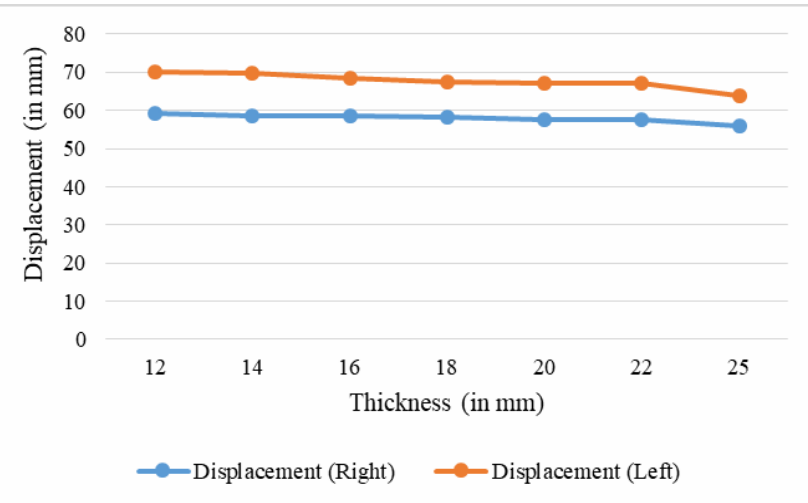

Fig. 5: Displacement V/s thickness of web stiffener, when vehicle loading is given to both girders

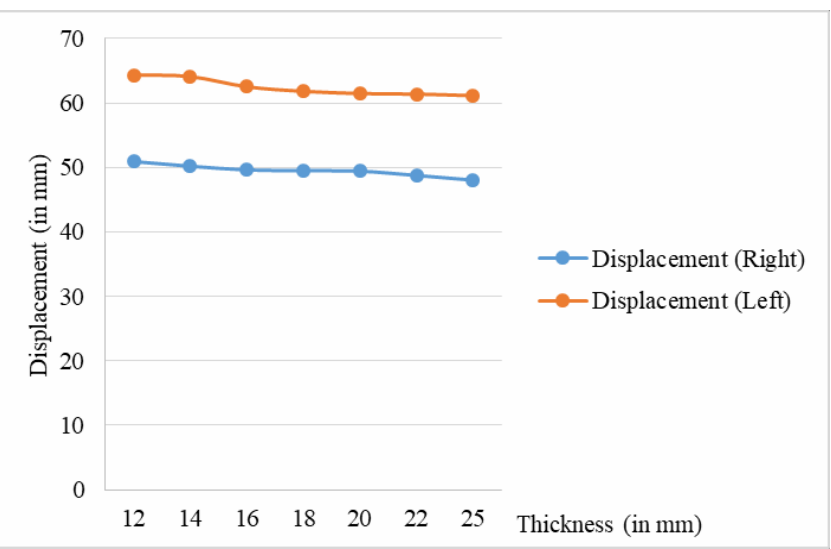

Fig. 6: Displacement V/s thickness of web stiffener, when vehicle loading is given to only one girder 


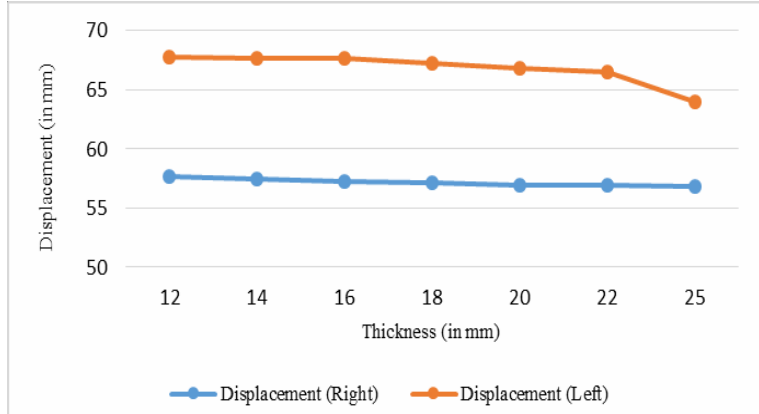

Fig. 7: Displacement V/s thickness of vertical stiffener, when vehicle loading is given to both girders

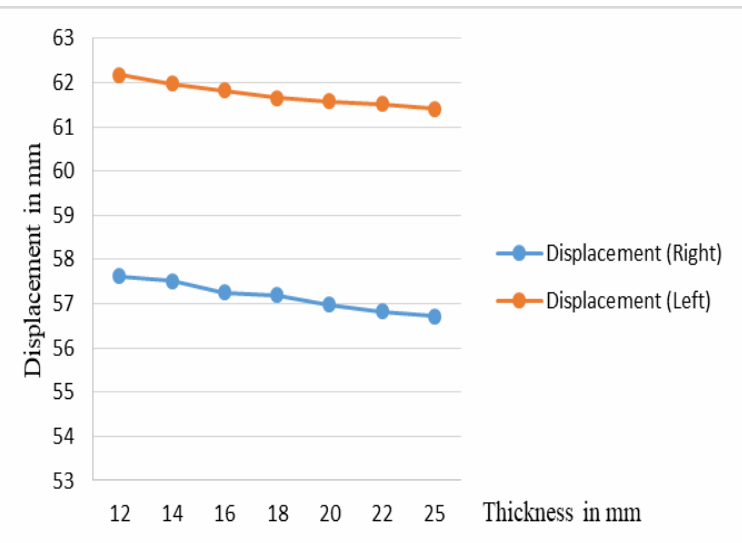

Fig. 8: Displacement V/s thickness of vertical stiffener, when vehicle loading is given to only one girder

From the above study, for every increase in thickness, displacement decreases and in case of increase in load, displacement also increases. Even though the girders are symmetrical, both of them gives different displacement for the given thickness of stiffener for selected loading because of the curvature and super elevation provided. Outer girder (left in graph) shows more displacement compared to inner girder (right in graph) because of the given curvature and super elevation more for outer girder.

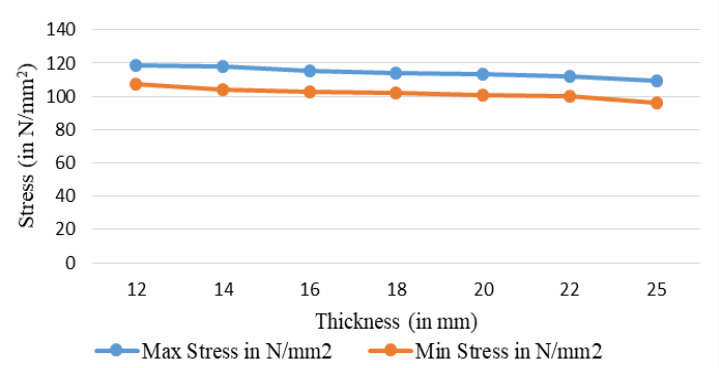

Fig. 9: Stress V/s thickness of bottom stiffener, when vehicle loading is given at both girder

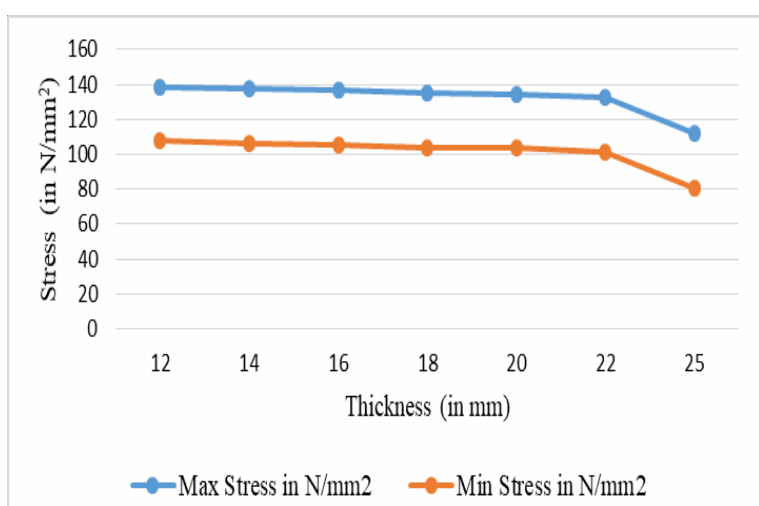

Fig. 10: Stress V/s thickness of bottom stiffener, when vehicle loading is given to only one girder

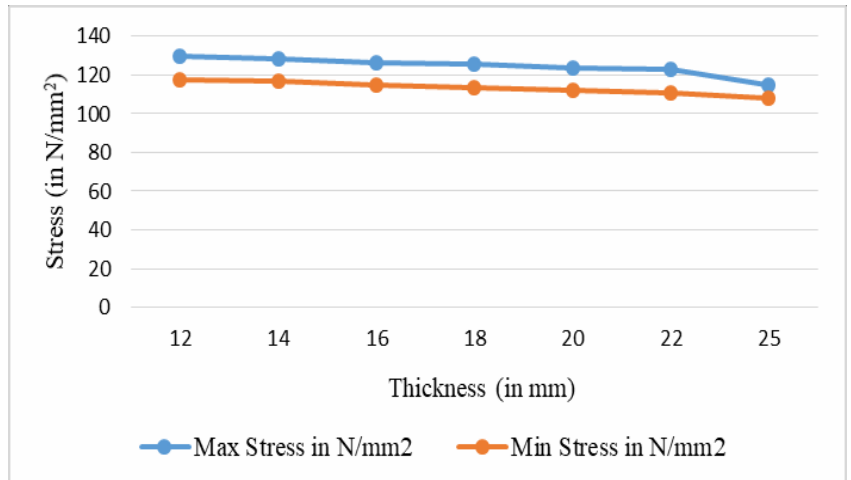

Fig. 11: Stress V/s thickness of web stiffener, when vehicle loading is given at both girder

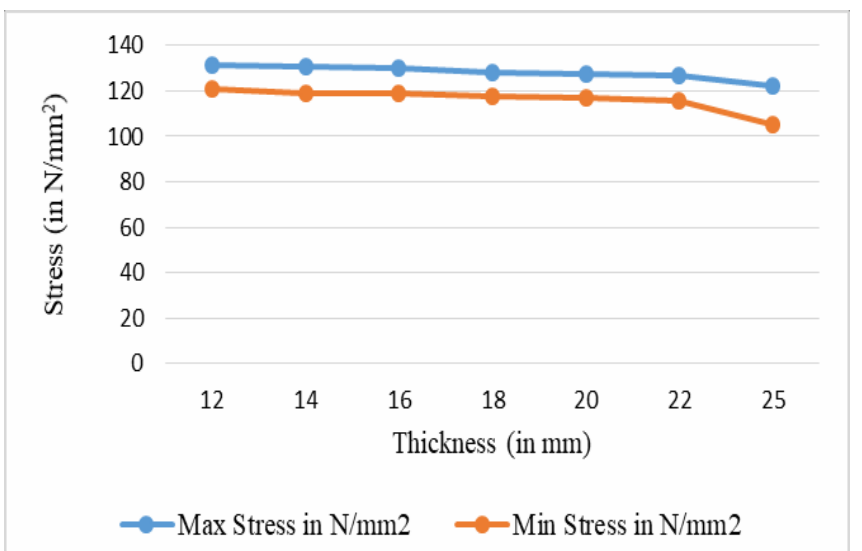

Fig. 12: Stress V/s thickness of web stiffener, when vehicle loading is given to only one girder

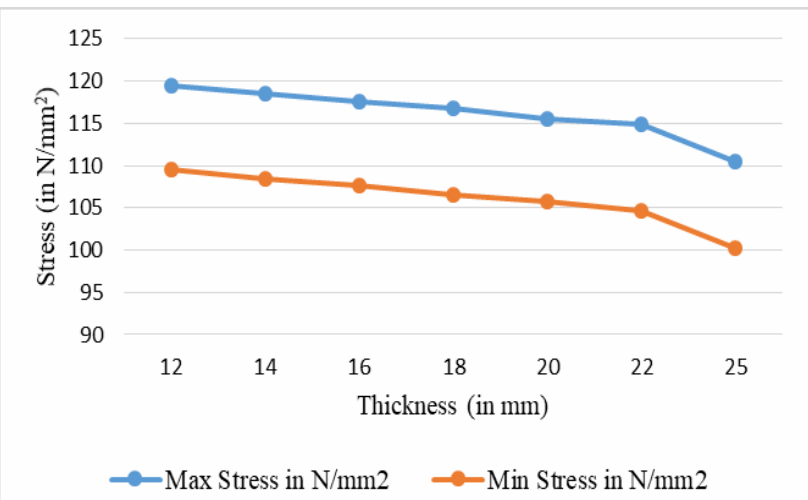

Fig. 13: Stress V/s thickness of vertical stiffener, when vehicle loading is given at both girder

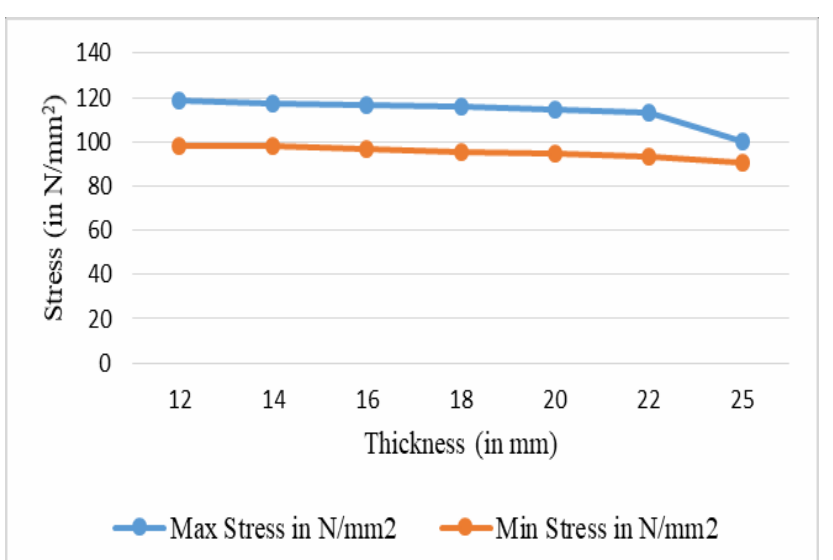

Fig. 14: Stress V/s thickness of vertical stiffener, when vehicle loading is given to only one girder 
From the above graphs shows a linear variation, for every increase in thickness, stress decreases. Even though the girders are symmetrical, both of them gives different stress for the given thickness of the stiffener for given loading. When loading is given to both girders at the same time, stress reduces with amplifying thickness of the stiffener. For other case also stress deducted with increment of thickness of the stiffener. Maximum stress is more when loading is present only at one girder at a time. Minimum stress is more when loading is present at both girders at the same time.

Deflection and stress distribution on girder is investigated in detail to know more about the stiffness property. By increasing thickness of stiffeners, deflection and stress distribution on the girder decreases hence improving the stiffness of the girder. From displacement as well as stress study it has been understood that stiffness improves when the thickness of the stiffeners are increased. Displacement of the girder is decreasing when the thickness of stiffeners are increasing and the maximum displacement is observed at the centre of the girder. Stresses developed in the girder also reduces while increasing the thickness of the stiffeners. Maximum stress is observed at the centre of the girder.

\section{Conclusion}

For railways on new alignments and construction depth is not a constrained, slab-on- beam arrangement like composite bridge can be chosen likewise the method as used for highways. Trapezoidal shaped Tub girders has a very excellent torsional stiffness which reduces their susceptibility to twisting of tracks. Hence to study on stiffness, deflection must be analysed for different thickness of stiffeners. Since stiffeners are major stiffness providing component in this girder. Stresses on each stiffeners during different loading conditions also studied to check whether it crosses the permissible stress. From study it is found that if thickness of girder increases, deflection and stress decreases thus enhancing stiffness of the girder. As a result torsional rigidity also increases.

Stiffeners are selected for the study because they are the major stiffness providing element in the girder. Provision of stiffeners in compression and shear zones improved the bending and shear strength of the girder. Longitudinal stiffeners and transverse stiffeners were provided. Longitudinal stiffeners include bottom stiffener and web stiffeners, both run throughout the span. Longitudinal stiffeners plays an important role improving the bending strength and shear capacity of the girder in total. Transverse stiffeners provided in the flanges of the girder spans throughout its depth. Transverse stiffeners improves the post buckling strength of the girder and reduces later buckling of flanges. Longitudinal stiffeners are provided throughout the bottom plate also to control the deflection resulted from heavy loading.

Compared to concrete girders, steel tub girder has reduced selfweight, excellent torsional stiffness, and exceptional aerodynamic stability due to the its horizontal curvature on the plan and trapezoidal shape of girder and transverse stiffeners added to the girder flanges reduced the vulnerability of lateral buckling of flanges making them more acceptable for heavy loaded bridges. Steel tub girders has improved durability and reduced maintenance of protective coatings since it is closed structure. Advantage of structural shape improves increased usage, improved aesthetics, maintenance and structural benefits. Hence the steel tub girder is an excellent choice over concrete girder. It can also be adopted for road bridges as well.

\section{References}

[1] Standard BI, "General Construction in Steel-Code of Practice", 3rd Revision, Bureau of Indian Standard, New Delhi, India, IS, (2007), pp.800-2007.

[2] Choi BH \& Yoo CH, "Strength of stiffened flanges in horizontally curved box girders", Journal of engineering mechanics, Vol.131, No.2, (2005), pp.167-176

[3] Yoo CH, Kang J \& Kim K, "Stresses due to distortion on horizontally curved tub-girders", Engineering Structures, Vol.87, (2015), pp.70-85.

[4] Hunley CT \& Harik IE, "Structural redundancy evaluation of steel tub girder bridges", Journal of Bridge Engineering, Vol.17, No.3, (2011), pp.481-489.

[5] Koo MS \& Hameed A, "Optimum cost design of steel box-girder by varying plate thickness", KSCE Journal of Civil Engineering, Vol.13, No.1, (2009), pp.31-37.

[6] Huang D, "Full-scale test and analysis of a curved steel-box girder bridge", Journal of Bridge Engineering, Vol.13, No.5, (2008), pp.492-500.

[7] Indian Railway Standard Code of Practice for the Design of Steel or Wrought Iron Bridges Carrying Rail, Road or Pedestrian Traffic.

[8] Indian Road Congress: Standard Specifications and Code of Practice for Road Bridges - Composite Construction, IRC 22, (2008).

[9] Indian Road Congress: Standard Specifications and Code of Practice for Road Bridges - Steel Road Bridges, IRC 24, (2008)

[10] Davidson JS, Balance SR \& Yoo CH, "Effects of longitudinal stiffeners on curved I-girder webs", Journal of Bridge Engineering, Vol.5, No.2, (2000), pp.171-178.

[11] Kochi Metro Rail Limited - Detailed Project Report, (2011)

[12] Kochi Metro Rail Limited - Design Based Report, (2011).

[13] Research Designs and Standards Organisation Specifications for Railway Over bridges and Steel, (2012).

[14] Galambos TV, Hajjar JF, Huang WH, Pulver BE, Leon RT \& Rudie BJ, "Comparison of measured and computed stresses in a steel curved girder bridge", Journal of Bridge Engineering, Vol.5, No.3, (2000), pp.191-199.

[15] Duk Kim Y, Jung SK \& White DW, "Transverse stiffener requirements in straight and horizontally curved steel I-girders", Journal of Bridge Engineering, Vol.12, No.2, (2007), pp.174-183. 